\title{
LA ECONOMÍA Y EL LÍMITE DE RESISTENCIA (2006)
}

\section{$\mathrm{J}_{\text {ohn Stuart Mill, en sus Principios de }}$} economía política, afirma que la economía pertenece a las ciencias morales y sociales. Es muy significativo que este padre del liberalismo sitúe la ciencia económica como ciencia moral, queriendo expresar que la "investigación sobre las leyes de la producción y la distribución de la riqueza" es un asunto con implicaciones morales.

Muchos economistas contemporáneos no solo han querido eliminar el carácter moral de la economía, sino que prohíben los juicios de valor, es decir, los juicios morales sobre la ciencia y las técnicas de la producción y de la distribución de la riqueza.

El carácter ético de la economía como "el arte de hacer posible lo necesario" (Pedro Aspe), "a todos por igual y las diferencias se justifican cuando favorecen a los más necesitados" (John Rawls) ha sido sustituido por fórmulas matemáticas de supuesta capacidad irrefutable sobre la maximización de los beneficios y el mejor manejo de la escasez.

Muchos economistas contemporáneos han llegado al extremo de un dogmatismo tan "científico e irrefutable", que cuando la realidad no se ajusta a la teoría se inclinan a pensar que el problema, la equivocación, radica en la realidad. Funestos resultados ha acarreado esta obsesión soberbia. Uno de estos ha sido la defensa irrestricta del libre mercado.

La historia, la mejor de las maestras, dice que, en la relación entre poderosos y débiles, los poderosos abusan de los débiles. Por eso afirma 
la ética que se debe dar tanta libertad al mercado cuantas igualdades se vayan logrando. Un buen ejemplo de este procedimiento es el que se sigue en la Unión Europea: para incorporar a una nación como nuevo miembro, primero le ayudan a lograr algunas igualdades básicas.

Los defensores del llamado neoliberalismo sostienen que estas igualdades básicas deben ser el resultado de la mayor o máxima libertad del mercado. Es aquí donde el único árbitro con auténtica autoridad es la realidad, la experiencia vivida.

En los años recientes, en que ha predominado una muy amplia libertad en el mercado, tenemos como resultado que "el $20 \%$ de la población más rica del mundo concentra el $86 \%$ del ingreso, mientras que el 20\% de la población más pobre solo dispone del 1\%" (ONU, Informe del Desarrollo Humano). "En el mundo existían 192 billonarios con un ingreso superior a los 500 dólares por segundo ( ibid.) de los cuales México llegó a tener 24".

Algunos ejemplos más del drama de las desigualdades y del hambre: "En el planeta viven cerca de 1500 millones de personas con un ingreso menor a un dólar al día (¡11 pesos por jornada de 10 y hasta 12 horas!) De ellos, más de 80 millones viven en América Latina y el Caribe y más de 18 millones en México (Banco Mundial, Informe del Desarro-

218 llo Humano). Mientras, algunos funcionarios mexicanos ganan hasta 300000 pesos mensuales ad vitam. Según datos del PNUD, los tres hombres más ricos del mundo tienen lo equivalente a la suma del PIB de las 48 naciones más pobres del mundo. Se han gastado más de 900000 millones de dólares en armas y en el mismo año murieron de hambre 40 millones de personas. México, por cierto, es uno de los países más inequitativos del mundo, con varios miembros de la lista de los más ricos del orbe y con más del $60 \%$ de la población en la pobreza, extrema pobreza e indigencia.

Frente a estos datos de terror, en los que con evidencia mortal se ve que no hay mano invisible que reparta ni derrama efectiva para los desheredados, todavía los teóricos de las fórmulas matemáticas, defensores radicales del libre mercado, afirman que no hay otro camino y que los beneficios llegan a largo plazo. Aunque, como bien dice J. M. Keynes: "a largo plazo todos estaremos muertos". 
Es perfectamente sustentable que el Estado puede y debe intervenir todo lo que sea necesario para lograr la justicia distributiva y el bien común, como lo han hecho, con admirable éxito, los famosos tigres asiáticos.

Se suele decir en México que los gobiernos son pésimos administradores. La respuesta es muy obvia: ¡Que el gobierno ponga a buenos administradores! Si no los hubiera, no habría tantos millonarios y billonarios en este país. Y si el problema es la corrupción, entonces que no se culpe a la conveniente, oportuna y necesaria intervención del Estado. Los pobres e indigentes ya no pueden esperar, no pueden resistir. Si no es por este medio, que inventen otro, pero la solución ya no puede esperar más.

De gran autoridad en este tema es la opinión de Joseph E. Stiglitz, premio Nobel de Economía: "Tienen que cambiar las instituciones y los esquemas mentales. La ideología de libre mercado debe ser reemplazada por análisis basados en la ciencia económica con una visión más equilibrada del papel del Estado a partir de una comprensión de la falla tanto del mercado como del Estado" (El malestar en la globalización).

"Con demasiada frecuencia la liberalización no vino seguida del crecimiento prometido, sino de más miseria [...] Incluso los países que han experimentado un moderado crecimiento han visto cómo los beneficios han sido acaparados por los ricos, y especialmente por los muy ricos (el 10\% más acaudalado) mientras que la pobreza se ha mantenido y en algunos casos se ha extendido como un incendio" (ibid).

Pienso, por todo esto, que si el nuevo gobierno no toma medidas de emergencia para acabar con esta grave inequidad, con esta insoportable injusticia social (o al menos para disminuirla sustancialmente), estaremos muy próximos al límite de resistencia de los marginados. Y cuando un pueblo llega al límite de resistencia explota, y no hay bombas por atómicas que sean que detengan la explosión. Esto también es lección de la historia, maestra de los pueblos. 
CITAM Derechos Reservados.

La reproducción total o parcial de este artículo se podrá hacer si el ITAM otorga la autorización previamente por escrito. 